\title{
CHARACTERIZATION OF THE SATISFACTORY DECISION PRINCIPLE
}

\author{
Yasuhiko Takahara \\ Bumpei Nakano \\ and \\ Kyoichi Kijima \\ Tokyo Institute of Technology
}

(Received April 16, 1977; Final March 15, 1978)

Abstract This paper discusses essential significances of the satisfactory decision criterion in an axiomatical way. For decision problems under undertainty the traditional decision criteria, for instance, the max-min, the regret and the Laplace criterion are well known. The satisfactory decision criterion is another type of principle towards decision problems under uncertainty. The traditional decision criteria requires first to arrange all alternatives in a linear order and then to subset the first elements as its solution. On the other hand, the satisfactory decision criterion is one that first arranges alternative in a linear order and second devides the linear order into two parts and third selects the "good" part as its solution, which is called a satisfactory subset. In this sense the satisfactory decision criterion is much simpler than the traditional ones. It is introduced by Simon to explain a realistic decision behaviour of human being and is formulated by Mesarovic as one of the most important decision criteria for control theory.

First we investigate properties of a satisfactory subset and find that a subset of the set of alternatives is a satisfactory subset if and only if it is an algebriac closed set. Second we axiomatize the satisfactory decision criterion by decomposing the resultant properties and make its "degree of simpleness" clear. Finally by comparing our axiom system with the axion systems of the traditional decision criteria obtained by Milnor, we find that the max-min and the regret criterion can be seen as special cases of the satisfactory decision criterion, that is, as the satisfactory decision criteria with special types of aspiration levels. The Laplace and the Hurwitz, however, can not be seen as the same as the other decision criteria including the satisfactory decision criterion.

In this paper we do not assume any structure in the sets of alternatives nor of uncertainties. Strong results under such more specified conditions will be presented later.

\section{Introduction}

In this paper a characterization of the satisfactory decision criterion is presented. Decision makings are traditionally classified into three categories; decision making under certainty, under risk and uncertainty. Each category is associated with specific decision criteria. For decision making 
under certainty optimization criterion is used. For decision making under risk optimization with respect to expectation is used. Decision making under uncertainty has four criteria, that is, the max-min criterion, the regret principle, the Hurwitz $\alpha$-criterion and the Laplace criterion. Meaning of optimization or optimization with respect to expectation is clear and hence its problem is to find good algorithms to realize it. As for criteria for uncertainty their meanings are not so simple and sometimes their usage becomes quite controversia1. It is, therefore, important to extract their essential meanings as well as to find their realization algorithm. Milnor [3] studied these four criteria and succeeded in axiomatizing them. His results revealed to some extent real properties of the criteria.

The satisfactory decision criterion is another type of decision criterion for decision making under uncertainty. It was introduced by Simon [5] to explain a realistic behaviour of human being and is now accepted as are the traditional decision criteria in the field of organization theory and psychology. Recently it has attracted attention of engineers and is formulated by Mesarovic [2] as one of the most important decision criteria for control theory.

In spite of its popularity no work has been done to reveal an essential significance of the satisfactory criterion in the same manner as Milnor's. This paper is trying to accomplish this theme.

If optimization is used as a decision criterion, a given set of alternatives $M$ should be linearly ordered and the best elements of it selected as decision. Contrary to optimization, as pointed out by Simon, the satisfactory decision criterion is just to divide a set of alternatives $M$ into two parts; a satisfactory subset $M^{\prime}$ and an unsatisfactory subset $M-M^{\prime}$. This is simple enough to be applicable to most cases. If we can get sufficient information, optimization is certainly superior to the satisfactory criterion. In many practical cases, however, we are forced to make a decision with poor information, in other words, under the bounded rationality, and then optimization is quite powerless. As we face more complicated problems, the situation becomes more severe. This is the reason why the satisfactory criterion has recently attracted more and more attention.

\section{Definitions and Notations}

In this section basic concepts and definitions are given.

\subsection{Decision Problem under Uncertainty}

Let $h, U$ and $R$ be the set of all alternatives, the set of all un- 
certainties and the set of real numbers, respectively. Then the set of all decision problems under uncertainty is defined by

$$
D=P\left(m_{n}\right) \times P(u) \times R^{\operatorname{m} \times u}
$$

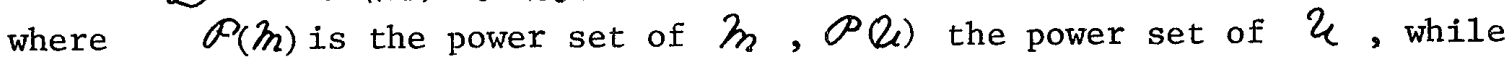
$R^{m \times U}$ is the set of all functions of the form

$\bar{g}: Z \times Z_{n} \rightarrow R$.

A decision problem under uncertainty $D \varepsilon \propto$ is, then, given by a triplet

$$
D=(M, U, g)
$$

where $M \varepsilon \mathscr{P}\left(Z_{n}\right)$ is called a set of alternatives, $U \varepsilon \mathcal{P}(U)$ a set of uncertainties or a set of states of nature, while $g: M \times U \rightarrow R$ is called a performance function. The performance function $g$ is given by the restriction of some $\bar{g}: m \times u \rightarrow R$, that is, $g=\bar{g} \mid M \times U$.

It should be noticed that in general a set of alternatives $M$ and a set of uncertainties $U$ of $D$ are different from $Z_{n}$ and $U$. It is because a decision maker may not identify all the alternatives and all the uncertainties when he is forced to make a decision.

In this paper: $g$ is always assumed a performance function, and so a decision maker is supposed to try to find $m \varepsilon M$ which maximizes $g(m, u)$ for each fixed $u \in U$.

When $D=(M, U, g)$ is given and if $U$ is not singleton, the decision maker can not select an alternative in an "absolutely rational" way. He has to use a decision criterion ( e.g. the max-min, the regret and so on ) in order to make a "rational" decision under such a situation. In this paper a decision criterion $c$ is represented by a mapping

$$
c: \mathcal{D} \rightarrow \infty(\operatorname{m} \times \ln ) \text {, }
$$

where $c(D) \varepsilon D(h \times h)$ is a partially ordered preference relation denoted by $\geqslant_{c}$. In a general preference relation two indifferent alternatives are not always equal and in this sense it is not correct to call $\rangle_{c}$ a partial order, but to simplipfy the notation $\geqslant_{c}$ will be treated as a partial order. $C(D)$ $\left(\left(M, \geqslant_{c}\right)\right)$ is called as relation (relational) structure (on $M$ ) with respect to $c$.

In the sequel we will consider an order structure $\geqslant_{M}$, of a set $M^{\prime}$ which is generated by adding a member $m$ to or by extracting from a set $M$ with order $\geqslant_{M}$. In this case we always assume the following natural relations hold :

$$
\begin{aligned}
& \text { If } M^{\prime}=M \cup\{m\} \text {, then } m^{\prime} \geqslant_{M} m^{\prime \prime} \text { implies } m^{\prime} \geqslant_{M^{\prime}} m^{\prime \prime} \text {. } \\
& \text { If } M^{\prime}=M-\{m\} \text {, then } m^{\prime} \geqslant_{M^{\prime}} m^{\prime \prime} \text { implies } m^{\prime} \geqslant_{M} m^{\prime \prime} \text {. }
\end{aligned}
$$


$\left.S_{\tau}(D)=\{m \in M \mid N u \in U)(g(m, u) \geqq \tau(u))\right\}$.

When a linear order has only maximal and minimal elements, it is called binary structure. A structure with respect to the satisfactory criterion is clearly binary.

\subsection{Max-min criterion}

The max-min decision criterion, one of the typical criteria for uncertainty, is defined as follows :

Definition 2.3.

For a given decision problem $D=(M, U, g)$, find $\hat{m} \varepsilon M$ such that $\inf _{u \in U} g(\hat{m}, u)=\sup _{m \varepsilon M} \inf _{u \in U} g(m, u)$.

$\hat{m}$ is called a solution with respect to the max-min criterion. Though, strict1.y speaking, this criterion should be called sup-inf criterion, we will call it max-min as usual. For the max-min criterion, a linear order $\geqslant_{m}$ is introduced as

$m \geqslant_{m} m^{\prime} \longleftrightarrow \quad i n f_{u \in U} g(m, u) \geqq i n f_{u \in U} g\left(m^{\prime}, u\right)$.

It is obvious from the definition that the solution set $S_{m}(D)$ of $D$ under the max-min criterion is defined by

$$
S_{m}(D)=\left\{m \varepsilon M \mid\left(\nabla m^{\prime} \varepsilon M\right)\left(m^{\prime} \geqslant_{m} m \rightarrow m \geqslant m^{\prime}\right)\right\} .
$$

\subsection{Regret principle}

The regret principle is defined by : Definition 2.4 .

For a given decision problem $D=(M, U, g)$, find $\hat{m} \varepsilon M$ such that $i n f_{u} \varepsilon{ }_{U}(\hat{m}, u)=\sup _{m \in M} \inf _{u \in U}\left(g(m, u)-\sup _{m \varepsilon M} g(m, u)\right)$. Such an $\hat{m}$ is called a solution with respect to the regret decision principle.

For the regret principle a linear order $\geqslant_{r}$ is introduced by $m \geqslant \eta_{r}^{\prime} \longleftrightarrow r_{m} \geqq r_{m}^{\prime}$, where $\quad r_{m}=\inf _{u \in U}\left(g(m, u)-\sup _{m \varepsilon M} g(m, u)\right)$

and

$$
r_{m^{\prime}}=\inf _{u \in U}\left(g\left(m^{\prime}, u\right)-\sup _{m \in M} g(m, u)\right) \text {, respectively. }
$$

$g(m, u)-\sup _{m \varepsilon M} g(m, u)$ is called regret of opportunity loss and represents the difference in the relative value that would result if $u$ were true state of nature and if $m$ were adopied instead of the best strategy under $u$. obviously 
$g(m, u)-\sup _{m \varepsilon M} g(m, u) \leqq 0$.

${ }^{r} m$ shows the least regret of $m$ with respect to $u$. The solution set $S_{p}(D)$ of $D$ under the regret principle is obviously given by

$$
S_{r}(D)=\left\{m \in M \mid\left(\nabla m^{\prime} \varepsilon M\right)\left(m^{\prime} \geqslant{ }_{r} m \rightarrow m \geqslant m_{r}^{\prime}\right)\right\} .
$$

\subsection{Hurwitz $\alpha$ - criterion}

The Hurwitz a-criterion is defined by :

Definition 2.5 .

For a given problem $D=(M, U, g)$, find $\hat{m} \varepsilon M$ such that

$\left.i n f_{U \in U} g(\hat{m}, u)=\sup _{m \varepsilon M^{\{\alpha} \sup _{u \in U} g(m, u)+(1-\alpha)} i n f_{U \varepsilon U} g(m, u)\right\}$. Such an $\hat{m}$ is called a solution with respect to the Hurwitz $\alpha$-criterion. For the Hurwitz $\alpha$-criterion, a linear order $\geqslant_{h}$ on $M$ is introduced by$$
m \geqslant m^{\prime} \longleftrightarrow h_{m} \geq h_{m^{\prime}}
$$

where $\quad h_{m}=\alpha \sup _{u \in U} g(m, u)+(1-\alpha) i n f_{u \in U} g(m, u)$

and $\quad h_{m}=\alpha \sup _{u \in U} g\left(m^{\prime}, u\right)+(1-\alpha)$ inf ${ }_{u \in U} g\left(m^{\prime}, u\right)$, respectively.

$\alpha$ is a real number between 0 and 1 reflecting "degree of optimism".

$\alpha=0$ gives the pessimistic max-min ( 2.3 ), and $\alpha=1$ gives an optimistic behaviour occasionally called max-max. The solution set $S_{h}(D)$ of $D$ under the Hurwitz $\alpha$-criterion is given by

$$
\left.S_{h}(D)=\left\{m \varepsilon M \mid\left(\forall m^{\prime} \varepsilon M\right)\left(m^{\prime} \geqslant_{h} m \rightarrow m\right\rangle_{h} m^{\prime}\right)\right\} .
$$

\subsection{Laplace criterion}

When the number of uncertainty is finite, say $n$, the Laplace criterion is defined by :

Definition 2.6.

For a given problem $D=(M, U, g)$, where $U=\left\{u_{1}, u_{2}, \cdots, u_{n}\right\}$, find $\hat{m} \varepsilon M$ such that

$$
\inf _{u \in U} g(\hat{\dot{m}}, u)=\sup _{m \in M} \frac{1}{n} \sum_{i=1}^{n} g\left(m, u_{i}\right) \text {. }
$$

Such an $\hat{m}$ is called a solution with respect to the Laplace criterion. For the Laplece criterion a linear order $\geqslant_{L}$ on $M$ is introduced

$$
\begin{aligned}
& \text { by } m \geqslant m_{L} m^{\prime} \longleftrightarrow L_{m} \geqslant L_{m^{\prime}}, \\
& \text { where }, \\
& L_{m}=\frac{1}{n} \sum g\left(m, u_{i}\right)^{\prime},
\end{aligned}
$$


and $L_{m}=\frac{1}{n} \sum g\left(m, u_{i}\right)$, respectively.

The solution set $S_{L}(D)$ of $D$ under the Laplace criterion is, then, given by

$$
S_{L}(D)=\left\{m \varepsilon M \mid\left(\forall m^{\prime} \varepsilon M\right)\left(m^{\prime} \succcurlyeq_{D} m \rightarrow m \gg_{L} m^{\prime}\right)\right\} .
$$

3. Axiomatization of the Satisfactory Decision Criterion

\subsection{Properties of a satisfactory subset}

In this section we will discuss some properties of a satisfactory subset as preparation of axiomatization in Section 3.2. Our problem in this section is : Given a decision problem $D=(M, U, g)$ and given a subset $M^{\prime} \subset M$, find necessary and sufficient conditions of $M^{\prime}$ for existence of some aspiration level $\tau: U \rightarrow R$ such that $M^{\prime}$ is a satisfactory subset of $M$ with respect to $\tau$.

If $M^{\prime} \subset M$ is arbitrary, a desirable aspiration level does not necessarily exist as the following simple example shows.

Example 3.1.

Suppose $M=\left\{m_{1}, m_{2}, m_{3}\right\}$ and $U=\left\{u_{1}, u_{2}, u_{3}\right\}$ and a pay-off matrix is given as below.

\begin{tabular}{c|ccc}
$g$ & $m_{1}$ & $m_{2}$ & $m_{3}$ \\
\hline$u_{1}$ & 2 & 3 & 4 \\
$u_{2}$ & 1 & 2 & 3 \\
$u_{3}$ & 3 & 1 & 5
\end{tabular}

Table $3-1$

For this problem there is no aspiration level $\tau$ such that $M^{\prime}=\left\{m_{1}, m_{2}\right\}$ is a satisfactory subset of $M$ with respect to $\tau$. In fact, since any aspiration $\tau$ that makes $M^{\prime}$ a satisfactory subset of $M$ must satisfy relations $\tau\left(u_{1}\right) \leqq 2, \quad \tau\left(u_{2}\right) \leqq 1$ and $\tau\left(u_{3}\right) \leqq 1$, $\left\{m_{3}\right\}$ is also satisfactory with respect to $\tau$. In order to present results in a concise way, we introduce the following definition. 
Given a decision criterion $c$, the solution function

$S_{c}: \infty \rightarrow \infty(h)$

is defined by $S_{c}(D)=\left\{m \varepsilon M \mid(\forall m \varepsilon M)\left(m^{\prime} \geqslant_{c} m \rightarrow m \geqslant_{c} m^{\prime}\right)\right\}$.

$S_{C}(D)$ is the set of maximal elements which are the most desirable with respect to $c$ and is called the solution set of $(D, C)$ or the solution set of $D$ under $C$.

In the latter part of this section we will give brief definitions of decision criteria to be used in the paper.

\subsection{Satisfactory criterion}

The satisfactory criterion proposed by Simon was formulated by Mesarovic. In his definition the existence of an aspiration level $\tau: U \rightarrow R$ is essential. The satisfactory decision criterion is defined by :

Definition 2.1.

For a given decision problem $D=(M, U, g)$ and for a given aspiration leve1 $\tau: U \rightarrow R$, find $\hat{m} \varepsilon M$ such that

$(\forall u \in U)(g(\hat{m}, u) \geqq \tau(u))$.

Such an $\hat{m}$ is called a satisfactory alternative with respect to $\tau$.

The definition says that $m$ is satisfactory if the performance by $m$ is "better" than the aspitation level for any $u \in U$.

Definition 2.2.

For a given decision problem $D=(M, U, g)$ a subset $M^{\prime}$ of $M$ is called a satisfactory subset of $M$ with respect to $\tau$

$$
\text { if } \begin{aligned}
\left(\forall m \in M^{\prime}\right)(\forall u \in U)(g(m, u) \geqq \tau(u)) \\
\left(\forall m \notin M^{\prime}\right)(\exists u \in U)(g(m, u)<\tau(u)) . \quad \text { and }
\end{aligned}
$$

The definition says that if all the alternatives of $M^{\prime}$ are satisfactory and all the alternatives of $M-M^{\prime}$ are unsatisfactory with respect to the aspiration level $\tau$, then $M^{\prime}$ is a satisfactory subset of $M$.

It should be noticed in the definition that if both $m \varepsilon M$ and $m^{\prime} \varepsilon M$ belong to $M^{\prime}$ or $M-M^{\prime}$, then $m$ and $m^{\prime}$ are indifferent and that if $m \varepsilon M^{\prime}$ and $m^{\prime} \varepsilon M-M^{\prime}$ then $m$ is strictly preferred to $m^{\prime}$. Therefore, the relation structure with respect to the satisfactory decision criterion is clearly a linear order which has only maximal and minimal elemets.

Let $\geqslant_{\tau}$ be the satisfactory order relation by an aspitation level $\tau$ such that

$$
\left(m \geqslant m^{\prime}\right) \& \operatorname{not}\left(m^{\prime} \geqslant_{\tau} m\right) \longleftrightarrow\left(m \in M^{\prime}\right) \&\left(m^{\prime} \in M-M^{\prime}\right) \text {. }
$$

The solution set $S_{\tau}(D)$ of $D$ under the satisfactory criterion is defined by 
Definition 3.2.

For a subset $M^{\prime}$ of $M$ a function

$$
\tau_{M}^{\prime} \quad: U \rightarrow R
$$

is defined by

$$
{ }^{\tau} M^{,}(u)=i n f_{m \in M^{\prime}} g(m, u) \text {. }
$$

$\tau^{\prime} M^{\prime}$ is called fundamental aspiration level for $M^{\prime}$.

Propositon 3.3.

For any subset $M^{\prime}$ of $M$ the following three statements are equivalent.

(1) $M^{\prime}$ is a satisfactory subset of $M$.

(2) $M^{\prime}$ is a satisfactory subset with respect to the fundamental aspiration level $\tau_{M}$.

(3) There exist $U^{\prime} \subset U$ and $\tau^{\prime}: U^{\prime} \rightarrow R$ such that

$(\forall m \in M)\left(\forall u \in U^{p}\right)\left(g(m, u) \geqq \tau^{\prime}(u)\right)$ and

$\left(\forall m \notin M^{\prime}\right)\left(\exists u \in U^{\prime}\right)\left(g(m, u)<\tau^{\prime}(u)\right)$.

Proof : Refer to Appendix 1.

Now let us consider meaning of Proposition 3.3. According to (2) of Proposition 3.3, whenever $M^{\prime}$ is a satisfactory subset, $M^{\prime}$ is also a satisfactory subset with respect to the fundamental aspiration level $\tau^{\prime}$. Intuitively, $\tau_{M}$ ' can be viewed as the "worst" performance by the alternatives of $M^{\prime}$ as shown by the fat line in Fig. 3-1 where the horizontal and vertical axes represent $u$ and real numbers, respectively. It should be noticed in Fig. 3-1 that although $m^{\prime}$ is not preferred to any alternative constituting $\tau^{\prime}$ ' (e.g. $m_{1}$ ), in order to be a satisfactory subset of $M M^{\prime}$ must contain $m^{\prime}$.

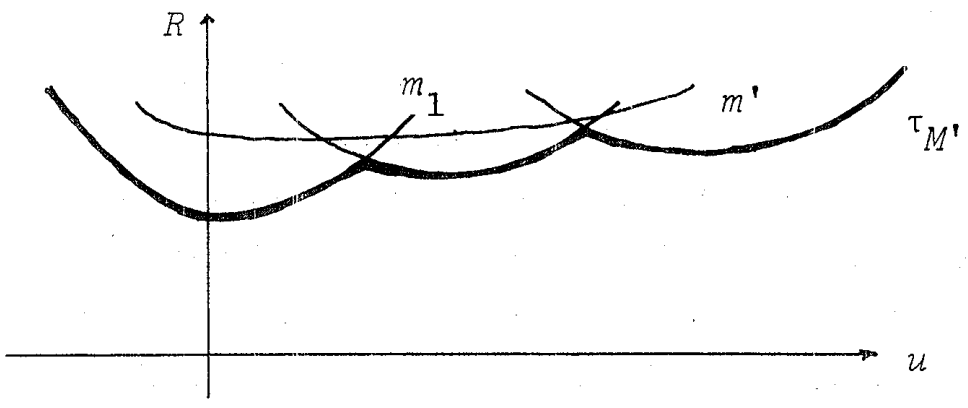

Figure 3-I

(3) of Proposition 3.3 shows that we can determine whether or not a subset $M^{\prime}$ of $M$ is a satisfactory subset by calculating the performance only for a subset $U^{\prime} \subset U$. If there exists an aspiration leve1 $\tau^{\prime}$ which makes $M^{\prime}$ satisfactory for $U^{\prime}$, then there also exists an aspiration level $\tau$ which makes $M^{\prime}$ satisfactory for $U$. 
Axiom A-1

There exists a linear order $\geqslant_{\imath}$ on $M$.

Axiom A-2

$\left(M, \geqslant_{l}\right)$ is a binary structure. That is, any alternative is either maximal or minimal with respect to $\rangle_{l}$. Let $D=(M, U, g)$ be a decision problem. The solution set $S(D)$ of $D$ is the set of all maximal alternatives, that is,

$$
S(D)=\left\{m \varepsilon M \mid\left(\forall m^{\prime} \varepsilon M\right)\left(m^{\prime} \geqslant m \rightarrow m \geqslant m^{\prime}\right)\right\}
$$

Axiom $\mathrm{A}-3$

Let $D=(M, U, g)$ be a decision problem ;

then $S(D) \supset S\left(M-\{m\}, U, g^{\prime}\right)$

for any $m \& S(D)$, where $g^{\prime}=g \mid(M-\{m\}) \times U$.

This says that even if a nonsolution $m$ of a problem $(M, U, g)$ becomes unavailable, that is, $(M, U, g)$ changes to $\left(M-\{m\}, U, g^{\prime}\right)$, every solution of $(M, U, g)$ still remains as a solution of $\left(M-\{m\}, U, g^{\prime}\right)$.

Axiom $A-4$

Let $D=(M, U, g)$ be a decision problem ; $m \varepsilon S\left(M_{\cup}\{m\}, U, \bar{g}^{\prime}\right)$, if $(\forall u \in U)\left(\exists m^{\prime} \varepsilon S(D)\right)\left(g(m, u) \geq \bar{g}^{\prime}\left(m^{\prime}, u\right)\right)$, where $\bar{g}^{\prime}=\bar{g} \mid(M \cup\{m\}) \times U$ and $m \notin M$.

This means that if the decision maker finds a new alternative $m$ satisfying a special condition, then it must be a solution of $\left(M \cup\{m\}, U, \bar{y}^{\prime}\right)$.

Note that no statement about an aspirtation level appears explicitly throughout the axiom system. Axiom A-1 and A-2 are straightforward requirements from the concept of the satisfactory decison making and can not be controversial. Axiom A-3 is a restatement of Assumption P-2 which is, we believe, not artifitial.

Proposition 3.4 .

The satisfactory decision criterion under Assumption $\mathrm{P}-1, \mathrm{P}-2, \mathrm{P}-3$ and $\mathrm{P}-4$ satisfies Axiom $\mathrm{A}-1, \mathrm{~A}-2, \mathrm{~A}-3$ and $\mathrm{A}-4$.

Proof : Refer to Appendix 2 .

On the other hand, it is also true that a decision behaviour satisfying Axiom $A-1, A-2, A-3$ and $A-4$ is a decision behaviour by the satisfactory decision criterion under Assurntion P-1, P-2, P-3 and P-4. 


\subsection{Axiomatization of the Satisfactory Decision Criterion}

In this section we will axiomatize the satisfactory decision criterion using the results obtained in Section 3.1. As pointed out in Section 2, the existence of an aspiration level $\tau: U \rightarrow R$ is essential for the satisfactory decision criterion. In real situations an aspiration level is usually sensitive to change of a set of alternatives and/or of a set of uncertainties. As a matter of fact, it is a realistic assumption that if the number of the available alternatives increases, aspiration level of a decision maker goes up because he can find a satisfactory alternative more easily. Furthermore, human being usually modifies his aspiration level in accordance with his information, his experiences and learnings. (Refer to the learning theory in psychology [6]) In this paper, however, we will not discuss a dynamic situation like a learning process, but consider a situation where the variation of the aspiration level is none or very small even if the set of alternatives and/or the set of uncertainties change. For instance, if a set of alternatives is quite large, we can assume that change of the number of alternatives does not affect the aspiration level so much.

The followings are the assumption of $\tau$ :

Assumption $\mathrm{P}-1$

The aspiration level $\tau$ is determined uniquely for a decision maker once a problem is given.

Assumption $\mathrm{P}-2$

When the set of alternatives decreases, the aspiration level does not go up. That is, let $\tau$ and $\tau$ ' be aspiration levels for $(M, U, g)$ and $\left(M^{\prime}, U, g\right)$, respectively. Then if $M \supset M^{\prime},(\forall u \in U)\left(\tau(u) \geqq \tau^{\prime}(u)\right)$ holds. Assumption $\mathrm{P}-3$

When the set of alternatives increases, the aspiration level does not go down. Furtheremore, if an added alternative $m$ is satisfactory with respect to $\tau, m$ will not become unsatisfactory with respect to a new aspiration level $\tau^{\prime}$ generated by this increase, that is, if $(\forall u \in U)(g(m, u) \geqq \tau(u))$, then $(\forall u \in U)\left(g(m, u) \geqq \tau^{\prime}(u)\right)$.

Assumption $\mathrm{P}-4$

The aspiration level may move as the change of the set of uncertainties. We assume no conditions for uncertainty.

The satisfactory decision criterion under Assumption P-1, P-2, P-3 and P-4 is axiomatized as follows. 
Proposition 3.5 .

If a decision behaviour satisfies Axiom A-1, A-2, A-3 and A-4, then it is a decision behaviour by the satisfactory decision criterion under Assumption $\mathrm{P}-1, \mathrm{P}-2, \mathrm{P}-3$ and $\mathrm{P}-4$.

Proof : Refer to Appendix 3.

Combining Proposition 3.4 and Proposition 3.5. we obtain the following necessary and sufficient condition .

Proposition 3.6.

A satisfactory decision behaviour satisfying Assumption $\mathrm{P}-1, \mathrm{P}-2, \mathrm{P}-3$ and $\mathrm{P}-4$ is equivalent to Axiom $\mathrm{A}-1, \mathrm{~A}-2, \mathrm{~A}-3$ and $\mathrm{A}-4$.

As we mentioned above, Axiom A-4 may be a little bit too structured to be called an axiom. In order to analize A-4 we introduce the following two definitions.

Definition 3.7 .

For each order structure $\left(M, \geqslant_{\imath}\right)$ and for each $m \varepsilon M$ an equivalence class $E(m)$ of $m$ is defined by

$$
E(m)=\left\{m^{\prime} \varepsilon M \mid\left(m \geqslant m_{2} m^{\prime}\right) \&\left(m^{\prime} \geqslant 2 m\right)\right\} \text {. }
$$

For any $S \subset M$ and $g: M \times U \rightarrow R$ let us define $\Lambda S: U \rightarrow R$ such that $\quad \Lambda S(u)=\inf _{m \in S} g(m, u)$.

Definition 3.8 .

A set of alternatives $M$ is called satisfying $\Lambda$ - closure property with respect to $g: M \times U \rightarrow R$ if for any $S \subset M$ there exists $m \varepsilon M$ such that $\Lambda S=g(m,-)$. In particular, when $g$ is fixed, we omit the phrase "with respect to $g$ ". Furthermore, if $\Lambda S=g(m,-)$, we can practically identify $\Lambda S$ by $m$ and so we will represent $\Lambda S$ by $m$, that is, we will use the expression $g(\Lambda S,-)$ for $g(m,-)$.

It should be noticed that if $M$ does not have the $A$-closure property then $\Lambda S$ is imaginary and does not necessarily belong to $M$.

In terms of the above definitions, the axiom system is restructured by the following.

Axiom B-1

There exists a linear order $\geqslant / 2$ on $M$. Axiom B-2

$\left(M, \geqslant_{\imath}\right)$ is a binary structure. That is, any alternative is either maximal or minimal with respect to $\geqslant_{\imath}$. Let $D=(M, U, g)$ be a decision problem. The solution set $S(D)$ of $D$ is the set of all maximal alternatives, 
that is,

$$
S(D)=\left\{m \varepsilon M \mid\left(\forall m^{\prime} \varepsilon M\right)\left(m^{\prime} \geqslant \imath m \rightarrow m \geqslant \eta m^{\prime}\right)\right\} .
$$

Axiom B-3

Let $D=(M, U, g)$ be a decision problem. Then

$$
S(D) \subset S\left(M-\{m\}, U, g^{D}\right)
$$

for any $m$ \& $S(D)$, where $g^{\prime}=g \mid(M-\{m\}) \times U$.

Axiom B-4

If $\quad(\forall u \in U)\left(g(m, u) \geqq g\left(m^{\prime}, u\right)\right)$ holds, then $m \geqslant m^{\prime}$.

Axiom B-5

For any $m \in M$ and for any subset $S$ of $E(m), \Lambda S \geqslant \eta$.

Proposition 3.9 .

Suppose $M$ has the $\Lambda$ closure property.

If the axiom system A-1, A-2, A-3 and A-4 (or A-axiom system) hold, then the axiom system B-1, B--2, B-3, B-4 and B-5 ( or B-axiom system ) hold.

Proof : Refer to Appendix 4 .

Proposition 3.10 .

Suppose $M$ has the $\Lambda$-closure property.

If B-axiom system holds, then A-axiom system holds.

Proof : Refer to Appendix 5.

Axiom B-4 means that if an alternative $m$ is superior to another alternative $m^{\prime}$ uniformly with respect to uncertainty $u, m$ should be preferred to $m^{\prime}$ in a decision. This condition should be always satisfied for any rational decision making. Axiom B-5, which is derived from (2) of Proposition 3.3, rough1y implies that an alternative jnsensitive to a change of uncertainty is preferred to a sensitive alternative even if the latter is quite desirable for some specific uncertainty. This axiom, therefore, reveals that the satisfactory decision criterion is conservative. Each axiom of B-axiom system has an intutively clear conceptual meaning, while Axiom A-4 is conceptually complicated. In this sense B-axiom system is superior to A-axiom system. However, as Proposition 3.9 and Proposition 3.10 say, B-axiom system is meaningful only if $M$ satisfies the $\Lambda$-closure property. In many practical cases we can expect that the property should hold though we can easily construct a counterexample.

Axiom B-5 is essential for the satisfactory decision criterion. Since Axiom B-4 should hold for any rational decision making and since Axiom B-1, B-2 and $B-3$ are natural requirements of the satisfactory decision making and since the satisfactory decision making is considered the simpliest one, we are apt to expect that Axiom B-1, B-2, B-3 and B-4 characterize the satisfactory decision 
criterion. But as the following example shows, this expectation is not true. In other words, Axiom $B-5$ is essential for the satisfactory decision criterion and cannot be derived from Axiom B-1, B-2, B-3 and B-4.

Example 3. 11 .

Let $M=\left\{m_{1}, m_{2}, m_{3}\right\}$ and $U=\left\{u_{1}, u_{2}, u_{3}\right\}$ and a pay off matrix is given as below.

\begin{tabular}{c|ccc}
$g$ & $m_{1}$ & $m_{2}$ & $m_{3}$ \\
\hline$u_{1}$ & 2 & 3 & 2 \\
$u_{2}$ & 1 & 2 & 2 \\
$u_{3}$ & 3 & 2 & 2
\end{tabular}

Table 3-II

If we introduce a linear order $\geqslant$ such that $\left(m_{1} \geqslant m_{2}\right),\left(m_{2} \geqslant m_{1}\right)$ and $\left(m_{2} \geqslant m_{3}\right)$, then $\geqslant_{2}$ does not contradict Axiom B-1, B-2, B-3 and B-4. However, $M^{\prime}=\left\{m_{1}, m_{2}\right\}$ can not be a satisfactory subset.

4. Comparison between Traditional and Satisfactory Criteria

\subsection{Traditional criteria and satisfactory decision making}

The satisfactory criterion appears quite different from the traditional decision criteria such as the max-min, the regret, the Hurwitz $\alpha$ and the Laplace decision criterion since another information, an aspiration level, is necessary. In this section we compare the satisfactory criterion with the traditional criteria.

It is clear that an order structure of each traditional decision criterion is finer than that of the satisfactory decision criterion, and that the traditional criteria do not necessarily satisfy Axiom A-2.

As for the max-min criterion and the regret principle, we have next proposition.

Proposition 4.1.

The max-min criterion and the regret principle satisfy Axiom A-1, A-3 and A-4.

Proof : Refer to Appendix 6.

Proposition 4.1, however, is not true for the Hurwitz $\alpha$ and the Laplace 
criterion as the following simple examples show.

Example 4.2. Hurwitz $\alpha$-Criterion

Let $M=\left\{m_{1}, m_{2}, m_{3}\right\}$ and $U=\left\{u_{1}, u_{2}, u_{3}\right\}$ and a pay-off matrix is given as below.

\begin{tabular}{l|cccc}
$g$ & $m_{1}$ & $m_{2}$ & $m_{3}$ & $m$ \\
\hline$u_{1}$ & 2 & 0 & 4 & 0 \\
$u_{2}$ & 1 & 2 & 3 & 2 \\
$u_{3}$ & 3 & 8 & 5 & 5
\end{tabular}

Table 4-I

We will show that Axiom A-4 is violated for $\alpha=\frac{1}{2}$.

Indeed, since $h_{m_{1}}=2, h_{m_{2}}=4$ and $h_{m_{3}}=4, S_{h}(D)=\left\{m_{2}, m_{3}\right\}$.

Suppose $m$ is a new alternative. Then since $g\left(m, u_{1}\right)=g\left(m_{2}, u_{1}\right)$, $g\left(m, u_{2}\right)=g\left(m_{2}, u_{2}\right)$ and $g\left(m, u_{3}\right)=g\left(m_{3}, u_{3}\right)$ the assumption of Axiom A-4

$(\forall u \in U)\left(m^{\prime} \in S_{h}(D)\right)\left(g(m, u) \geqq g\left(m^{\prime}, u\right)\right)$

is satisfied. But $h_{m}=\frac{1}{2}(0+5)=\frac{5}{2}<4$ shows that $m$ never belongs to $S_{h}\left(M \cup\{m\}, U, g^{\prime}\right)$.

Example 4.3. Laplace Critrion

Let $M$ and $U$ be the same as in Example 4.2 and a pay-off matrix is given as below

\begin{tabular}{c|cccc}
$g$ & $m_{1}$ & $m_{2}$ & $m_{3}$ & $m$ \\
\hline$u_{1}$ & 2 & 0 & 4 & 0 \\
$u_{2}$ & 1 & 0 & 3 & 0 \\
$u_{3}$ & 3 & 12 & 5 & 5 \\
& \multicolumn{3}{|c}{ Table 4-II }
\end{tabular}

We will show that Axiom A-4 is violated.

Since $L_{m}=2, I_{m_{2}}=4$ and $L_{m_{3}}=4, S(D)=\left\{m_{2}, m_{3}\right\} . \quad$ Suppose a new alternative $m$ is attached. Then since $g\left(m, u_{1}\right)=g\left(m_{2}, u_{1}\right), g\left(m, u_{2}\right)$ $=g\left(m_{2}, u_{2}\right)$ and $g\left(m, u_{3}\right)=g\left(m_{3}, u_{3}\right)$ the assumption of Axiom A-4 is 
satisfied. However, $\quad L_{m}=\frac{5}{3}<4$ show that $m$ never belongs to $S_{L}(M U$ $\left.\{m\}, U, \bar{g}^{\prime}\right)$.

As shown above, we can conclude that the max-min and the regret principle are essentially the same as the satisfactory criterion except the fineness of the structures. A decision making by the max-min criterion is first to arrange alternatives in linear order by $\rangle_{m}$ and then to select the first elements as its solution. On the other hand, according to Proposition 4.1 a decision making by the max-min criterion satisfying Axiom A-2 is one that first arranges alternatives in linear order by $\geqslant_{m}$ second divides the linear order into two parts and third selects the first part as its solution. The regret principle satisfying Axiom $\mathrm{A}-2$ is similarly defined. Then :

Corollary 4.4 .

A decision making by the max-min criterion satisfying A-2 is a satisfactory decision making for some aspiration level $\tau$.

Corollary 4.5 .

A decision making by the regret principle satisfying A-2 is a satisfactory decision making for some aspiration level $\tau$.

\subsection{Aspiration levels for traditional criteria}

As Corollary 4.4 and Corollary 4.5 show, the max-min and the regret criterion are, in some sense, special cases of the satisfactory criterion, that is, they are satisfactory criteria with special types of aspiration levels. In this section, we will investigate what types of aspiration levels are satisfied for the max-min criterion and the regret principle. Before the discussion we present types of aspiration levels.

The simplest aspiration level is of the form

$$
\tau(w)=c,
$$

where $c$ is constant, and is called constant aspiration leve1. This kind of aspiration level is the most often used.

Next, an aspiration of the form

$$
\tau(u)=\sup _{m \varepsilon M} g(m, u)-c
$$

where $c$ is a nonnegative constant, is called least opportunity loss aspitation level. It is obvious from the definition that a least opportunity loss aspiration level is deeply related to the regret decision criterion.

Besides these two types there is another kind of aspiration level of the form, 


$$
\tau(u)=g(\hat{m}, u)
$$

where $\hat{m} \in M$ is a current alternative. The satisfactory criterion with this type of aspiration level aims at improvement of the present situation. Though it plays an important role in the theory of multi-1evel system [1], we will not discuss it here.

As defined in Section 2, the ordering $\geqslant_{m}$ of the max-min criterion is given by

$$
m \geqslant_{m} m^{\prime} \longleftrightarrow i n f_{u \in U} g(m, u) \geqq i n f_{u \in U} g\left(m^{\prime}, u\right) .
$$

Then the usual order topology for $M$ can be induced by $\geqslant_{m}$. In this section, the closedness of $M^{\prime} \subset M$ with respect to $\vartheta_{m}$ means $M^{\prime}$ is closed with respect to the order topology induced by $\geqslant_{m}$. The relationship between the satisfactory criterion and the max-min decision criterion is, then, given by the next proposition.

Proposition 4.6 .

Let $h: M \rightarrow M$ be the identity map, and $(M, \geqslant)$ some binary structure. If $h$ is an order homomorphism from $\left(M, y_{m}\right)$ into $(M, \geqslant)$, that is, $m \geqslant m \quad m^{\prime} \rightarrow m \geqslant m^{\prime}$ and if $M^{\prime}=\left\{m \varepsilon M \mid\left(\forall m^{\prime} \varepsilon M\right)\left(m^{\prime} \geqslant m \rightarrow m \geqslant m^{\prime}\right)\right\}$ is closed with respect to $\geqslant m$, then $(M, \geqslant)$ is the satisfactory structure with a constant aspiration level.

Conversely, if $(M, \geqslant)$ is the satisfactory structure with a constant aspiration level, then $h$ is an order homomorphism.

Proof : Refer to Appendix 7.

Proposition 4.6 shows that the satisfactory criterion with a constant aspiration level is essentially equivalent to the max-min decision criterion. The difference is, as we mentioned in Section 3, only that the structure of the max-min decision criterion is generally not a binary structure so that it is finer than that of the satisfactory criterion. We should emphasize that the satisfactory criterion with a constant aspiration level is as pessimistic a criterion as the max-min.

The ordering $\geqslant_{x}$ under the regret decision criterion is given by

$$
m \geqslant m^{\prime} \longleftrightarrow r_{m} \geqq r_{m^{\prime}} \text {, }
$$

where $r_{m}=\inf _{u \in U}\left(g(m, u)-\sup _{m \varepsilon M} g(m, u)\right)$

and $\quad r_{m^{\prime}}=\inf f_{u \in U}\left(g\left(m^{\prime}, u\right)-\sup _{m \varepsilon M} g(m, u)\right)$, respectively. 
In the same manner as the max-min decision criterion, we obtain the next proposition.

Proposition 4.7 .

Let $h: M \rightarrow M$ be the identity map and $(M, \geqslant)$ some binary structure. If $h$ is an order homomorphism from $\left(M, \geqslant_{r}\right)$ into $(M, \geqslant)$, that is, $m \geqslant m^{\prime} \rightarrow m \geqslant m^{\prime}$ and if $M^{\prime}=\left\{m \varepsilon M \mid\left(\forall m^{\prime} \varepsilon M\right)\left(m^{\prime} \geqslant m \rightarrow m \geqslant m^{\prime}\right)\right\}$ is closed with respec to $\geqslant_{p}$, then $(M, \geqslant)$ is the satisfactory structure with a least opportunity loss aspiration level. Conversely, if $(M, \geqslant)$ is the satisfactory structure with a least opportunity loss aspiration level, then $h$ is an order homomorphism.

Proof : Refer to Appendix 8.

In the same manner as for the max-min decision criterion, we can conclude that the satisfactory criterion with a least opportunity loss aspitation level is viewed essentially equivalent to the regret decision criterion.

\section{Conclusion}

We have studied the satisfactory criterion in an axiomatical way and clarified an essential property of it. The followings are the summary of some of our results :

(1) The axiom system we proposed in this paper indicates a "degree of simpleness" of the satisfactory criterion : Though the satisfactory criterion is considered quite simple and rational, it is not so simple as decribed by only the axioms $\mathrm{B}-1, \mathrm{~B}-2, \mathrm{~B}-3$ and $\mathrm{B}-4$; essential is $\mathrm{B}-5$.

(2) The max-min and the regret principle can be considered a type of the satisfactory criterion with a special aspiration level.

Although we have not assumed any structure of $M$ and $U$, we can give strong results by introducing detailed structure, for instance, topology into them. The following is one of the results.

Suppose that

(1) $M$ is a compact subspace of a linear metric space,

(2) $U$ is a compact metric space and

(3) $g(-, u): M \rightarrow R$ is strictly concave for each $u \varepsilon U$.

Then a subset $M^{\prime}$ of $M$ is a satisfactory subset for some continuous aspiration level if and only if
(a) $M^{\prime}$ is closed,
(b) $M^{\prime}$ has nonempty intericr and 
(c) $\quad \partial M^{\prime}=B d\left(M^{\prime}\right) \neq \phi$,

where $\partial M^{\prime}$ is defined by

$$
\partial M^{\prime}=\left\{m \in M \mid(\exists u \in U)\left(g(m, u)=\tau_{M^{\prime}}(u)\right)\right\}
$$

and $B d\left(M^{\prime}\right)$ denotes the boundary of $M^{\prime}$.

These results will be reported later.

\section{Appendices}

1. Proof of proposition 3.3 ;

$(1) \rightarrow(2)$ : Since $M^{\prime}$ is a satisfactory subset with respect to some aspiration leve1 $\tau: U \rightarrow R,\left(\forall m \in M^{\prime}\right)(\forall u \in U)(g(m, u) \geqq \tau(u))$ and $\left(\forall m \& M^{\prime}\right)(\exists u \in U)(g(m, u)<\tau(u))$ hold. From the definition of $\tau_{M^{\prime}}$, we have $\left(\forall m \in M^{\prime}\right)(\forall u \in U)\left(g(m, u) \geqq \tau_{M^{\prime}}(u)\right)$ and $(\forall u \in U)$ $\left(\tau_{M^{\prime}}(u) \geqq \tau(u)\right)$ implies $\left(\forall m\right.$ \& $\left.M^{\prime}\right)(\exists u \varepsilon U)\left(g(m, u)<\tau_{M^{\prime}}(u)\right)$. (2) $\rightarrow$ (3) : By setting $U^{\prime}=U$ and $\tau^{\prime}=\tau_{M^{\prime}}$ we obtain the result. (3) $\rightarrow$ (1) : We show that $M^{\prime}$ is a satisfactory subset with respect to $\tau^{*}$ : $U \rightarrow R \quad$ such that $\tau^{*}(u)=\tau^{\prime}(u)$, if $u \in U^{\prime} ;=\underset{m \varepsilon M^{\prime}}{\inf } g(m, u)$, otherwise. From (3), $(\forall m \in \varepsilon M)\left(\forall u \in U^{\prime}\right)(g(m, u \geqq \tau *(u))$ holds. From the definition of $\tau^{*}$, we have $\left(\nabla m \varepsilon M^{\prime}\right)\left(\nabla u \varepsilon U-U^{\prime}\right)\left(g(m, u) \geqq i n f_{m \varepsilon M} g(m, u)\right.$ $\left.=\tau^{*}(u)\right)$. On the other hand,because $\left(\forall m \notin M^{\prime}\right)\left(\exists u \varepsilon U^{\prime}\right)\left(g(m, u)<\tau^{*}(u)\right)$ from (3) and $U^{\prime} \subset U,\left(\forall m \notin M^{\prime}\right)(\exists u \varepsilon U)\left(g(m, u)<\tau^{*}(u)\right)$.

Q. E. D.

2. Proof of Proposition 3.4 ;

Axiom A-1 and Axiom A-2: Let $D=(M, U, g)$ be a decision problem and $\tau: U \rightarrow R$ an aspiration level and $S_{\tau}(D)$ a satisfactory subset of $M$, i.e., $\mathrm{S}_{\tau}=\{m \in M \mid(\forall u \in v)(g(m, u) \geqq \tau(u)\}$.

Define an order relation $\geqslant$ on $M$ by

$$
\begin{aligned}
& m \geqslant m^{\prime} \longleftrightarrow\left[m \varepsilon S_{\tau}(D) \& m^{\prime} \varepsilon S_{\tau}(D)\right] \\
& v\left[m \notin S_{\tau}(D) \& m^{\prime} \notin S_{\tau}(D)\right] . \\
& \checkmark\left[m \& S_{\tau}(D) \& m^{\prime} \notin S_{\tau}(D)\right] \text {. }
\end{aligned}
$$

then $\geqslant$ is clearly a linear order with only maximal and minimal elements. Axiom A-3 : For any $m^{\circ} \notin S_{\tau}(D) \quad$ let us consider a problem 


$$
D^{\prime}=\left(M-\left\{m^{\circ}\right\}, U, g^{\prime}\right), \text { where } g^{\prime}=g \mid\left(M-\left\{m^{\circ}\right\}\right) \times U \text {. }
$$

Because of Assumption P-2, the new aspiration level ' $\tau^{\prime}$ for $D^{\prime}$ is not higher than $\tau$, so that

$$
(\forall u \in U)\left(g(m, u) \geqq \tau^{\prime}(u)\right) \text { for any } m \in S_{\tau}(D)
$$

Therefore, $S_{\tau}(D) \subset S_{\tau},(D)$, which means $S(D) \subset S\left(M-\left\{m^{\circ}\right\}, U, g^{\prime}\right)$

since we have $S_{\tau}(D)=S(D)$.

Axiom A-4: For any $m \notin M$ such that

$$
\nabla u \in U)\left(\exists m^{\prime} \varepsilon M^{\prime}\right)\left(\bar{g}^{\prime}(m, u) \geqq g\left(m^{\prime}, u\right)\right),
$$

we find that $(\forall u \in U)\left(\bar{g}^{\prime}(m, u) \geqq g\left(m^{\prime}, u\right) \geqq i n f_{m^{\prime \prime} \varepsilon M^{\prime}} g\left(m^{\prime \prime}, u\right)\right)$.

However, since $(\forall u \in U)\left(\inf { }_{m \in M^{\prime}} g\left(m^{\prime \prime}, u\right) \geqq \tau(u)\right)$, we have $(\forall u \varepsilon U)\left(\bar{g}^{\prime}(m, u)\right.$ $\geqq \tau(u))$; consequently $m$ is a solution of the problem.

Q.E.D.

3. Proof of Proposition 3.5 ;

It is only required to show that $S(D)$ is a satisfactory subset with respect to $\tau_{S(D)}$, the fundamental aspiration level for $S(D)$, because of Proposition 3.4 .

It is clear that

$$
(\nabla u \in U)\left(g(m, u) \geqq \tau_{\mathcal{S}(D)}(u)\right)
$$

for any $m \in S(D)$, and so it is only required to show that

$$
(\exists u \in U)\left(g(m, u)<\tau_{S(D)}(u)\right)
$$

for any $m \notin S(D)$. Suppose there exists $m \notin S(D)$ such that

$$
(\forall u \in U)\left(g(m, u) \geqq \tau_{S(D)}(u)\right) \text {, then } S(D) \subset S\left(M-\{m\}, U, g^{\prime}\right)
$$

because of A-3. However, both $M-\{m\} \neq m \quad$ and $(\forall u \varepsilon U)\left(g(m, u) \geqq \tau_{S(D)}\right.$ (u)) imply that

$$
(\forall u \in U)\left(\exists m^{\prime} \varepsilon S(D) \subset S\left(M-\{m\}, U, g^{\prime}\right)\right)\left(g(m, u) \geqq g\left(m^{\prime}, u\right)\right),
$$

which is Assumption A-4. Using A-4, we find $m \in S(M-\{m\}) \cup\{m\}$, $\left.U, \bar{g}^{\prime}\right)$, that is, $m \varepsilon S(D)$ because of $(M-\{m\}) \cup\{m\}=M$. That is contradiction.

4. Proof of Propositio- 3.9 ;

$B-1, B-2$ and $B-3$ are clearly valid. Let $\geqslant /$ be the linear order derived from B-1. First we will show that B-4 is true. Suppose $(\forall u \in U)(g(m, u) \geq$ $\left.g\left(m^{\prime}, u\right)\right)$ and $\operatorname{not}\left(m \geqslant m^{\prime}\right)$ for some $m$ and $m^{\prime} \varepsilon M$. Then not $\left(m \geqslant m^{\prime}\right) \quad$ implies that $\left.m^{\prime}\right\rangle_{\tau} m$ from B-1 so that $m^{\prime} \varepsilon S(D)$ and $m$ \& $S(D)$. 
from B-2. Using B-3, we have $S(D) \subset S\left(M-\{m\}, U, g^{\prime}\right)$, which shows $m^{\prime} \varepsilon$ $S\left(M-\{m\}, U, g^{\prime}\right)$. Since $(\forall u \varepsilon U)\left(g(m, u) \geqq g\left(m^{\prime}, u\right)\right)$ and $m^{\prime} \varepsilon S\left(M-\{m\}, U, g^{\prime}\right), m$ must be a satisfactory decision for $\left((M-\{m\}) \cup\{m\}, U, g^{\prime}\right)$ from A-4. $(M-\{m\}) \cup\{m\} \quad$ is actually $M$, that is, $m \varepsilon S(D)$. This is contradiction. Consequently $\mathrm{B}-4$ should hold.

Next we will show that B-5 is valid. Since A-axiom system holds, Propo-sition 3.4 and 3.8 imply $S(D)$ is an satisfactory set with respect to some $\tau: U \rightarrow R$. Let $m \varepsilon M$ be arbitrary.

(1) Suppose $m \in S(D)$. Then for any $S \subset E(m)$ and for any $m^{\prime} \varepsilon S, m^{\prime}$ is also satisfactory. The $\Lambda$-closure property of $M$ implies that

$$
g(\Lambda S, u)=\inf f_{m} g(m, u) \geqq \tau(u) \text { for each } u \varepsilon U \text {. }
$$

This means that $\Lambda S$ is satisfactory, that is, $\Lambda S \geqslant m$.

(2) Suppose $m \notin S(D)$. Then for any $S \subset E(m)$ and for any $m^{\prime} \varepsilon S$, $m^{\prime}$ is also unsatisfactory. Thus $g(\Lambda S, u)=i n f_{m} \in S g(m, u)<\tau(u)$ for

some $u \in U$. This means that $\Lambda S$ is unsatisfactory, that is, $\Lambda S \geqslant m$.

Q.E.D.

\section{Proof of Proposition 3.10;}

We will show that $A-4$ is obtained from B-axiom system. Let us consider $m \notin M \quad$ such that $(\forall u \in U)\left(\exists m^{\prime} \varepsilon S(D)\right)\left(g(m, u) \geq g\left(m^{\prime}, u\right)\right)$. Then $(\forall u \in U)\left(g(m, u) \geqq i n f_{m^{\prime} \varepsilon S(D)} g\left(m^{\prime}, u\right)\right)$ holds.

However, all the alternatives of $\mathrm{S}(\mathrm{D})$ are equivalent, in $f_{m^{\prime}} \varepsilon S(D) g\left(m^{\prime}, u\right)$ can be viewed as the performance by the alternative $\Lambda S$, that is, in $f_{m} \varepsilon S(D)$ $g\left(m^{\prime}, u\right)=g(\Lambda S(D), u)$ for each $u$. Thus we find $(\forall u \varepsilon U)(g(m, u) \geq g(\Lambda S, u))$, which implies $m \geqslant \imath \Lambda(D)$ by $B-4$. Since $\Lambda s(D)$ is satisfactory by $B-5$, we can conculde that $m$ is satisfactory.

Q.E.D.

6. Proof of Proposition 4.1;

Since tha proofs for both criteria are similar, we consider only the maxmin criterion.

A-1 is true since $\geqslant_{m}$ is clearly a linear order on $M$. Next, for any $m \notin$ $S(D), S_{m}(D)=S_{m}\left(M-\{m\}, U, g^{\prime}\right) \quad$ holds. Hence A-3 is true. Finally, suppose $m \notin M$ and $(V u \in U)\left(\equiv m^{\prime} \ddagger S_{m}(D)\right)\left(g(m, u)=g\left(m^{\prime}, u\right)\right)$. Let $r=\inf _{u \in U} g\left(m^{\prime}, u\right)$. Then it is constant for any $m^{\prime} \varepsilon S_{m}(D)$. Thus, 


$$
g(m, u) \geqq g\left(m^{\prime}, u\right) \geqq i n f_{u \in U} g\left(m^{\prime}, u\right)=r \text { for some } m^{\prime} \varepsilon S_{m}(D) \text {. }
$$

Consequently, $g(m, u) \geq r$ holds; which implies

$$
m \varepsilon S_{m}\left(M \cup\{m\}, U_{3} \bar{g}^{p}\right)
$$

7. Proof of Proposition 4.6 :

Since $(M, \geqslant)$ is a binary structure; $M^{\prime}$ is the set of all maximal alternatives with respect to $\geqslant_{m}$. Furthermore, since $M^{\prime}$ is closed with respect to $\geqslant_{m}$, there exists $m^{\circ} \varepsilon M$ such that $m \geqslant m_{m}^{\circ}$ for any $m \varepsilon M^{\prime}$.

(1) For any $m \varepsilon M^{\prime}(\forall u \varepsilon U)\left(g(m, u) \geq c=i n f_{u \in U} g(m, u)\right)$ holds: For, $i n f_{u \in U^{g}}(m, u) \geq i n f_{u \in U} g\left(m^{\circ}, u\right)=c$ because of $m m_{m}^{\circ}$.

(2) For any $m \& M^{\prime}(\exists u \in U)\left(g(m, u)<c=i n f_{u \in U} g\left(m^{\circ}, u\right)\right)$ holds:

For, if there were $m$ \& $M^{\prime}$ such that $(\forall u \varepsilon U)(g(m, u) \geqq c)$ then $m$ \& $M^{\prime}$ would imply $m \underset{m}{<} m^{\circ}$. Since $h$ is order homomorphism, we have $m \prec m^{\circ}$ On the other hand, $(\forall u \in U)(g(m, u) \geqq c)$ means $m \geqslant_{m} m^{\prime}$, which implies $m \geqslant m^{\circ}$ because $h$ is an order homomorphism. This is contradiction. Both (1) and (2) show $(M, \geqslant)$ is the satisfactory structure with a constant aspitation leve1.

Suppose $h$ were not an order homomorphism. Then there would be $m, m^{\prime} \varepsilon M$ such that

$$
\begin{gathered}
m \geqslant_{m} m^{\prime} \text { and } m^{\prime}>m_{\circ} \\
m \geqslant_{m} m^{\prime} \text { implies that } \inf _{u \in U} g(m, u) \geqq \inf { }_{u \in U} g\left(m^{\prime}, u\right) .
\end{gathered}
$$

On the other hand, since $m^{\prime} / m$ and the aspiration level is constant $c$, $(\forall u \in U)\left(g\left(m^{\prime}, u\right) \geqq c\right)$ and $(\exists u \varepsilon U)(g(m, u)<c)$. Noting that $\quad \inf f_{\mathcal{U} \varepsilon U} g\left(m^{\prime}, u\right) \geqq c$ and $\quad$ inf $f_{u \in U} g(m, u)<c$, we obtain inf $f_{u \in U} g\left(m^{\prime}, u\right)>\inf _{u \in U} g(m, u)$.

That is contradiction.

Q.E.D.

8. Proof of Proposition 4.7.

Since $(M, \geqslant)$ is a binary structure, $M^{\prime}$ is the set of all maximal alternatives with respect to $\geqslant$. Furthermore, since $M^{\prime}$ is closed with respect to $\geqslant_{r}$, there exists $m^{\circ} \varepsilon M^{\prime}$ such that $m \geqslant_{p} m^{\circ}$ for any $m \varepsilon M^{\prime}$.

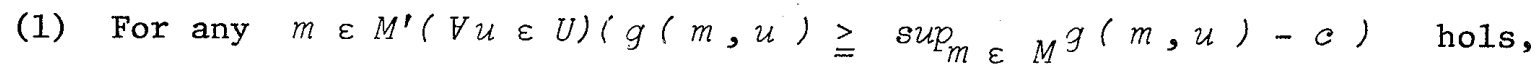


where $c=-\inf _{u \in U}\left(g\left(m^{\prime}, u\right)-\sup _{m \varepsilon M} g(m, u)\right)$ :

For, since we have $m \geqslant m^{\circ}$,

$$
i n f_{u \in U}\left(g(m, u)-\operatorname{sip}_{m \varepsilon M} g(m, u)\right) \geqq i n f_{u \in U}\left(g\left(m^{\circ}, u\right)-\sup _{m \varepsilon M} g(m, u)\right)
$$

Therefore, $\quad(\forall u \in U)\left(g(m, u) \geqq \sup _{m \varepsilon M^{g}}(m, u)-c\right)$.

(2) For any $m \& M^{\prime}(\exists u \varepsilon U)(g(m, u)<\sup g(m, u)-c)$ holds,

where $\quad c=-i n f_{u \varepsilon U}\left(g\left(m^{\circ}, u\right)-\sup _{m \varepsilon M} g(m, u)\right) \geqq 0:$

For, if there exists $m$ \& $M^{\prime \prime}$ such that

$$
(\forall u \in U)\left(g(m, u) \geqq \sup _{m \in M} g(m, u)-c\right)
$$

Then $m$ \& $M^{\prime}$ implies $m \prec_{p} m^{\circ}$. Since $h$ is an order homomorphism, we have $m<m^{\circ}$.

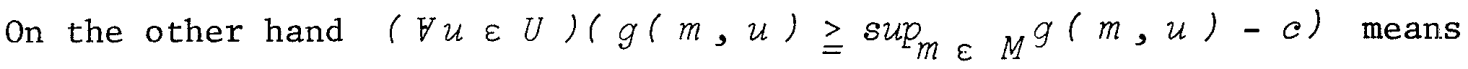
$m \geqslant_{p} m^{\circ}$, which implies $m \geqslant m^{\circ}$ because $h$ is an order homomorphism.

This is contradiction.

Both (1) and (2) shows that $(M, \geqslant)$ is the satisfactory structure with a least opportunity loss aspiration leve1.

Suppose $h$ were not an order homomorphism. Then there would be $m, m^{\prime} \varepsilon M$ such that

$$
m \geqslant m^{\prime} \text { and } m^{\prime}>m \text {. }
$$

$m \geqslant_{r} m^{\prime}$ implies that

$$
i n f_{u \in U}\left(g(m, u)-\sup _{m \varepsilon M} g(m, u)\right) \geqq i n f_{u \in U}\left(g\left(m^{\prime}, u\right)-\sup _{m \varepsilon M} g(m, u)\right) .
$$

On the other hand, since $m^{\prime} \succ m$ and the aspiration level $\tau$ is $\tau(u)=$ $\sup _{m \varepsilon M} g(m, u)-c$ for some $c \geqq 0$, we have

$$
(\forall u \in U)\left(g\left(m^{\prime}, u\right) \geqq \sup _{m \in M} g(m, u)-c\right)
$$

and $(\exists u \in U)\left(g(m, u)<\sup _{m \in M} g(m, u)-c\right)$

These imply that

$$
\inf _{u \in U}\left(g\left(m^{\prime}, u\right) \cdots \sup _{m \in M} g(m, u)\right) \geq-c
$$

and $\inf _{u \in U}\left(g(m, u)-\sup _{m \in M} g(m, u)\right)<-c$

so that $\inf _{u \in U}\left(g\left(m^{\prime}, u\right)-\sup _{m \in M} g(m, u)\right)$

This is contratiction.

$$
>\quad i n f_{u \in U}\left(g(m, u)-\sup _{m_{\varepsilon} M} g(m, u)\right. \text {. }
$$

Q.E.D. 
References

[1] Mesarovic, M.D., Macko, D. and Takahara Y. ; Theory of Hierarchical Multilevel Systems : Academic Press, 1970.

[2] Mesarovic, M.D. and Takahara Y. ; On a Qualitative Theory of Satisfactory Contro1 : Information Science 4, 1972.

[3] Milnor, J. ; Games against Nature, in Decision Process ed. by Thrall, Goombs and Davis : John Wiley and Sons, 1954.

[4] Miyazawa, K. ; Formdation of Information and Decision Theory : Iwanami, 1971 ( in Japanese).

[5] Simon, H.A. ; Models of Man : John Wiley and Sons, 1954.

[6] Stedry, A.C. ; Budget Control and Cost Behaviour : Englewood Cliffs. N.J.: Prentice-Ha11, 1960.

[7] Takahara Y., Nakano B. and Kijima K. ; Characterization of the Satisfactory Criterion, in Abstract of the Operations Research Society of Japan, September, 1976 ( in Japanese)

[8] Takatsu S. ; Internal paper in Tokyo Institute of Technology, 1976.

\author{
Yasuhiko TAKAHARA, \\ Bumpei NAKANO and \\ Kyoichi KIJIMA : Department of \\ Systems Science, Tokyo Institute \\ of Technology, 1-12-1, Oh-okayama, \\ Meguro-ku, Tokyo, 152, Japan.
}




\section{满足化決定基準の特徵付}

東京工業大学 高 原 康 彥
中 野 文 平
木 嶋 恭一

本論文は，满足化意思決定基準の本質的意味を公理論的に明らかにするととを目的とする。つまり 満足化基準で何が本質的であるかを厳密に追求し，でをるだけ透明な理論を得ようとするすのである。 従来，不確実性下の意思决定問題飞対しては， max-min基準，Laplace 基準，Hurwitz 基 準等の決定基準が提案され広く知られている。乙れらはいずれも代替案間に 1 つの線形順序を導入し， その極大要素の選択を要請するものである。それに対して，サイモンらによって提唱され，メサロヴ ィチらによって定式化された満足化決定基準は不確実性下の決定問題に対処する今一つの態度であっ

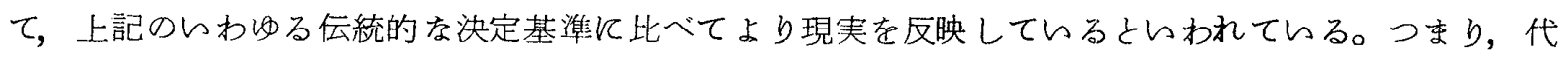
替案集合は，要求水準を満しているか否玑基づいて 2 つ分けられ，一方の" 望ましい"部分に属 する代替案すべてを区別なく満足解として選択するというものである。（てれを代替案集合の満足部 分集合という)

本論文は大をく 3 つの部分で構成されている。すず最初に満足部分集合の性質を調べた。代替案の 任意の部分集合が満怘部分集合になれるわけではなく，そのために部分集合に要請される必要十分条 件を得灰。

次に，乙の条件をできるだけ整理細分し，本質的なすののみを抽出するてとにょり，満足化決定基 準の公理化を行う。このようなフォーマルなアプローチをするととによって，一般性，客観性が得ら れ，言葉による表現に伴らあいまいさを除去するととがでをる。実際てのような考察によって，単 純であるといわれている満足化決定基準の単純さの程度が明らかにされた。

最後に, 得られた満足化決定基準の公理システムを他の伝統的な決定基準の公理システムと比較検 討するととにより，ｍax-min，regret両基準は，本質的には，満足化決定基準の特別な場合であ るととがわかった。ととろが, Lalace，Hurwitz 両基準はそのように考えられず，てれら2つ は他の決定基準（満足化決定基準を含めて）とは，かなり異質であるととが明らかになった。

以上述べたように，本論文では代替案集合や不確実性集合に何らの構造をも仮定せずに議論を進め たが, 数学的 (代数的ないし位相的) 構造の導入により,ょり強力な結果が期待される。 